\title{
Analysis of the need for prosthesis use in non-institucionalized elderly, SUS usuers, using dental and normative social indicators.
}

\begin{abstract}
Marcelo Meneghim(PQ), Glaucia Ambrosano (PQ),Arlete Oliveira(PG), Caroline N.Garcia (IC) Abstract

The aim of the study was to analyze the impact in determining the diagnosis in need of prostheses in noninstitutionalized elderly, using as criteria the socio-dental and clinical indicators. This is an epidemiologic, observational, analytical cross-sectional study. The sample consisted of elderly over 60 years, both genders, independent or partially dependent. The sample consisted of 279 elderly that met the research selection criteria. Research instruments used for subjective evaluation were GOHAI, IODD; by objective clinical criteria. Data were grouped and placed in model for joint evaluation between the pattern of needs perceived by the patient, socio-demographic, clinical and socio-dental. The results were assessed by bivariate analysis using the chi-square test and multivariate analysis. The variables with $p<0.20$ were tested in multiple logistic regression analysis, remaining in the model those with $p<0.05$. In conclusion, comparing the determination of need for prostheses for partner analysis - and dental clinic, the determination of need was greater in the latter. There is a tendency to use smaller and greater need for dental use among the elderly who have bad oral health self-assessment.
\end{abstract}

Key words: Elderly, Epidemiology, Self-perception

\section{Introduction}

The health diagnosis is fundamental for the organization of the work process and the establishment of different care arrangements for families and individuals according to their vulnerability and health needs, following the principle of equity, in addition to showing the importance of understanding the aging from the perspective biopsychosocial

The research aims to analyze the need for prostheses in elderly institutionalized not using socio-dental indicators and clinical diagnostic

\section{Results and Discussion}

According to the data obtained from the survey, it is real the poor oral health status of noninstitutionalized elderly, who have a large number of tooth loss, poor hygiene and most making use of prostheses. In general, older people maintain a positive view of their oral health, although the results point to a precarious medical condition. Meneghim CM, Saliba NA. Oral health status of the elderly population of Piracicaba-SP: 1998. RPG Rev Post Grad 2000; 7: 7-13lt was observed that lack of teeth is the major cause of dental problems, affecting more than $50 \%$ of the population studied. According to the quality of life instruments used in this research and normative evaluation, IODD data, indicate that the impact caused by dental problems in everyday life of the elderly often occurred in $25 \%$ of participants, and that in $75 \%$ of participants was not noticed any impact

\section{Conclusions}

The subjective measure self declaration of need for prostheses, measured by socio-dental approach, was strongly associated with the assessment with the normative criteria of clinical diagnosis of the need to use prostheses

\section{Acknowledgement}

To the Professors of the Department of Social Dentistry, College of Dentistry of PiracicabaUnicamp

To Units of Family Health of Piracicaba.

To CNPq

To PRP / Unicamp

Colussi CF, Freitas SFT. Epidemiological aspects of oral health of the elderly in Brasil.2002; 18 (5): 1313-20

Meneghim CM, Saliba NA. Oral health status of the elderly population of Piracicaba-SP: 1998. RPG Rev Post Grad 2000; 7:7-13

Furtado D G, FDS Forte, DFBM milk. Use and prostheses Need for Elderly: Reflections on Quality of Life. R bras ci Health 15 (2): 183 190,201

Sheiham A, Maizels JE, Cushing AM. The concept of need in dental care. Int Dent J 1982; 32(3): 265 - 701SRC

Silva, Fernandes RAC. Self-perception of oral health status of the elderly. Rev Public Health 2001; 35 (4) 349-355.1 